\title{
Quarterly Report for High NA Optics Development: Q4-1999 International Sematech Project LITH 112
}

\author{
J. S. Taylor
}

January 14, 2000

U.S. Department of Energy

Lawrence

Livermore

National

Laboratory

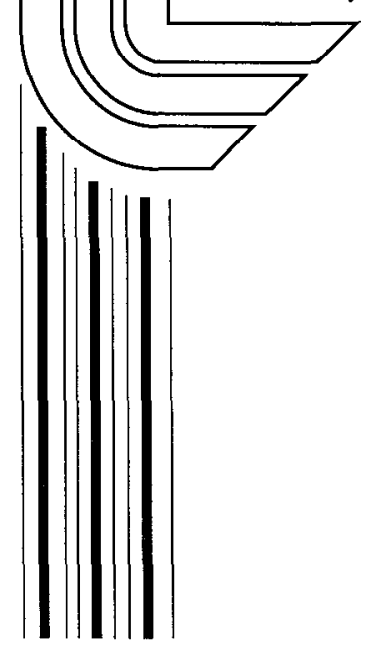


the exposure latitude is $\pm 18 \%$. However, for any given exposure level there was a reduction in the available depth of focus. The total depth of focus is $\sim 200 \mathrm{~nm}$ based on a $10 \%$ variation in exposure.

The ED analysis for the $35 \mathrm{~nm}$ technology node was also performed using $35 \mathrm{~nm}$ dense and $23 \mathrm{~nm}$ isolated features (ITRS roadmap). The same trends observed at the $50 \mathrm{~nm}$ node are observed at the $35 \mathrm{~nm}$ node. There is a slight shift in "best" focus to achieve the nominal $\mathrm{CD}$ at the nominal exposure and the process latitude is greater for the dense features. For the dense feature geometry, the maximum process window has a $15 \%$ ELAT over a depth of focus is $\sim 200 \mathrm{~nm}$ (assuming a $\pm 10 \%$ linewidth variation). Printing isolated features requires tighter process control. At a relative exposure variation of $\pm 5 \%$, the depth of focus shrinks to $\sim 125 \mathrm{~nm}$. This reduction in depth of focus can be partially overcome by using mask bias and overexposure, which is a topic of further study.

\section{Milestone 6: Specification package for the multilayer coatings}

The influence of multilayer coatings on MET performance was addressed during Q4-1999. We found that the incidence angles were sufficiently well-controlled to allow uniform $\mathrm{Mo} / \mathrm{Si}$ multilayers to be used. The multilayers cause a simple focus shift on the order of $\sim 100 \mathrm{~nm}$, but otherwise do not impact the imaging characteristics. Figure 4 illustrates optical path difference (OPD) maps from the nominal projection system and with $\mathrm{Mo} / \mathrm{Si}$ multilayer coatings added. In each case, the residual as-designed RMS wavefront error (less focus) was found to be $0.09 \mathrm{~nm}$.
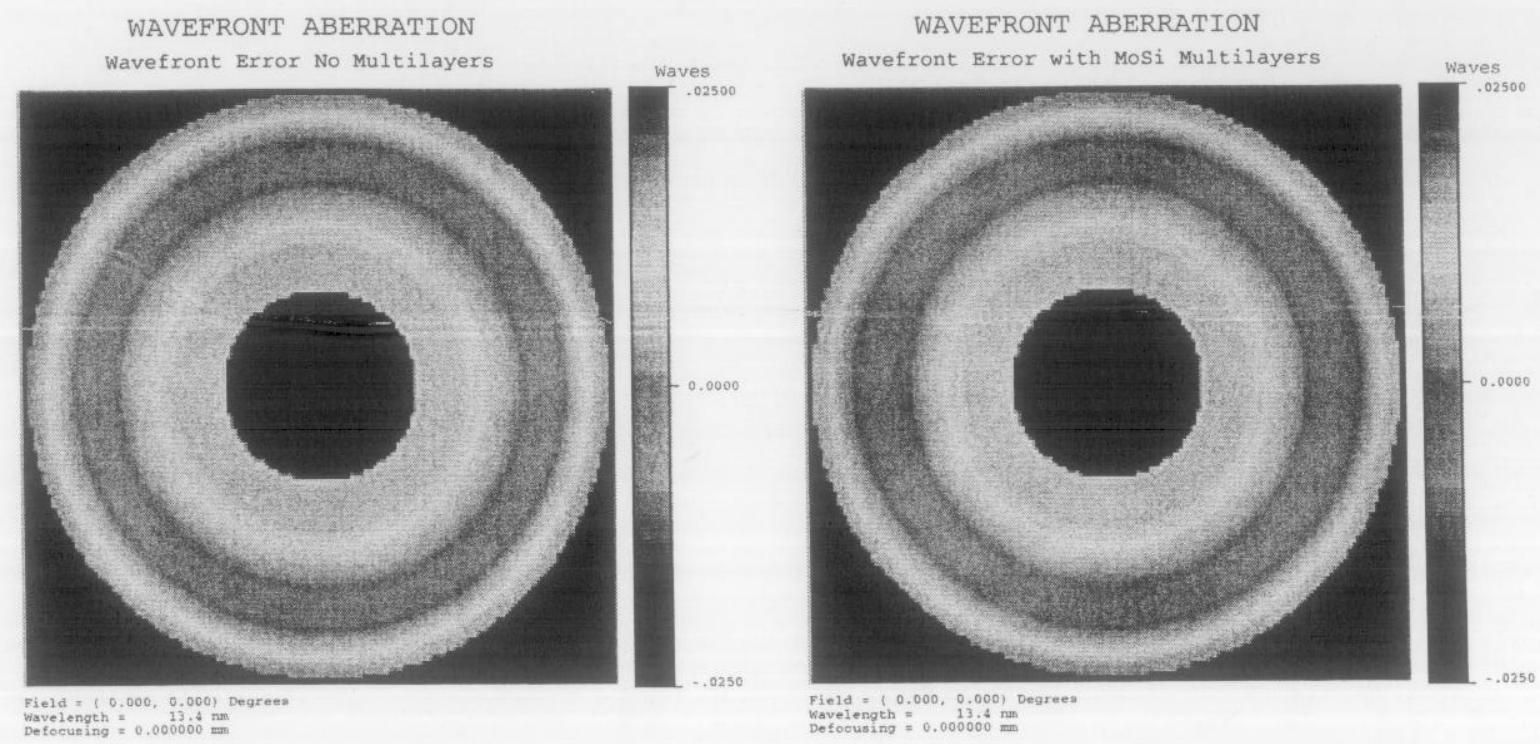

Figure 4. Optical path difference (OPD) maps for the nominal high NA microstepper (left) and with (right) multilayer coatings. In each case, the residual RMS wavefront error is $0.09 \mathrm{~nm}$, proving that uniform $\mathrm{Mo} / \mathrm{Si}$ multilayers do not alter the residual wavefront error as-designed at any field point. Therefore, the coatings do not impact the lithographic printing characteristics of the camera. 


\section{Quarterly Report for High NA Optics Development: Q4-1999 International Sematech Project LITH 112}

To: $\quad$ Neil Wester, International SEMATECH

From: John S. Taylor, LLNL

CC: Donald Sweeney, LLNL John Goldsmith, SNL Russell Hudyma, LLNL Layton Hale, LLNL Chuck Gwyn, EUV LLC Genaro Mempin, EUV LLC Gary Sommargren, LLNL Walt Lindquist, LLNL

Date: January 14,2000

\section{Executive Summary}

This quarterly report provides a status update for each of the milestones for the International Sematech project on the development of high-NA optics for a small-field EUVL exposure tool. Accomplishments this quarter include aerial image calculations, specifications for multilayer coatings, specification of the M2 substrate, and design of fixturing for M2, and the design of the metrology mount for M2. The optical fabrication vendor, Carl Zeiss, has completed the construction of an interferometer for use in fabricating the M1 substrate and reports a test-to-test repeatability of $0.06 \mathrm{~nm}$ rms. However, the simultaneous achievement of figure and finish is requiring longer than anticipated, which will extend the M1 delivery date to the end of Q1-2000. Zeiss is planning to process substrates $\mathrm{M} 1$ and $\mathrm{M} 2$ in parallel and currently does not project a slip in their overall schedule.

\section{Summary of Progress}

Milestone 1: Award contract for the fabrication and testing of two aspheric mirrors A contract was placed with Carl Zeiss (Oberkochen) for the fabrication and testing of substrates for the High NA Camera and was reported in the Q3-1999 Quarterly Report for this project. Progress by the vendor in fabricating these optics is reported below under Milestone 9.

Milestone 2: Award contract for the multilayer coatings

It was reported in the Q3-1999 Quarterly Report that the multilayer coatings will be fabricated at LLNL. It is planned for M1 and M2 to be coated at the same time to optimize wavelength matching. 
Milestone 3: Optical design package for EUV imaging system employing two aspheric mirrors

This milestone was completed during Q3-1999 and a report was submitted to International Sematech (Neil Wester). For reference, the following excerpt from the Q3-1999 Quarterly Report is included here.

This simple high NA optical system, diagrammed in Figure 1, is designed to be used in a microstepper and makes use of the "equal radii" concept to correct field curvature over a $600 \mu \mathrm{m} \times 200 \mu \mathrm{m}$ field at the wafer. The projection system is designed to work at a reduction ratio of 5:1. Two aspheric mirrors are used in a coaxial, obscured configuration to achieve the high numerical aperture (NA) of 0.30 . The area obscuration is carefully limited to less than $10 \%$ of the exit pupil area, allowing the optical system to achieve sub$30 \mathrm{~nm}$ resolution with partially coherent illumination. The system is compatible with either a reflection or transmission mask, enabling two distinct modes of operation. To use a reflection mask, the mask plane itself is tilted to allow the illumination to enter the projection optics. There is a corresponding tilt to the wafer plane that allows the design to recover most of its nominal performance. Diffraction-limited performance across the image field is achicved in either imaging mode. Using a transmission mask, the field composite RMS wavefront error is $0.28 \mathrm{~nm}(0.021 \lambda, \lambda=13.4 \mathrm{~nm})$. With a reflection mask, the field composite RMS wavefront is $0.42 \mathrm{~nm}(0.031 \lambda)$.

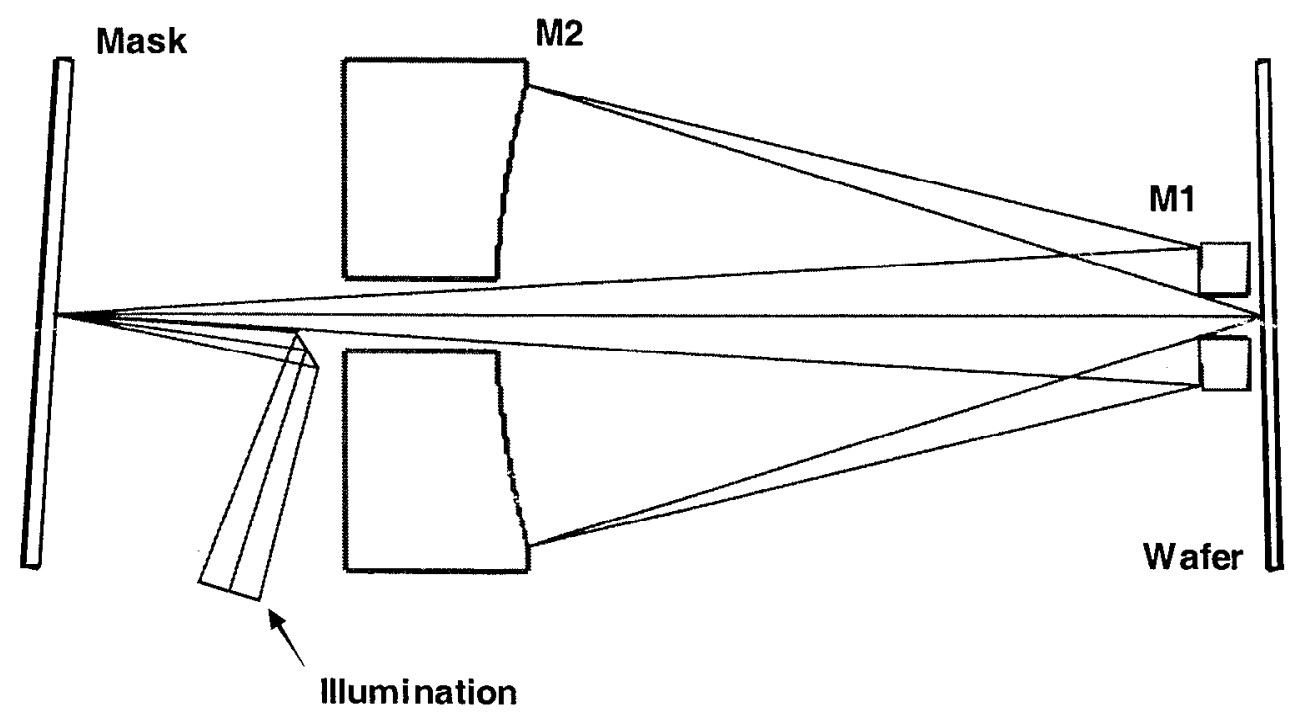

Figure 1. Schematic of High-NA Camera for the Micro Exposure Tool (MET). 
Milestone 4: Specification package for the individual polished mirror substrates 4a: M1 4b: M2

The design of the M1 substrate is complete and Zeiss has initiated manufacturing. A report and design drawing for Milestone $4 \mathrm{a}$ has been submitted to Sematech (Neil Wester) on $10 / 8 / 99$.

The design of the M2 substrate has been completed and a report has been submitted to International Sematech (Neil Wester). Sufficient detail of the M2 design was provided to the vendor in October to procure material. In addition, the design of the M2 metrology mount is complete. The geometry of the M2 substrate is compatible with our planned approach for fixturing the optic within the PO Box and within metrology tools. The completion of this specification package required detailed consideration of: the mounting approach within the PO Box, degrees of actuation required for PO Box alignment, space constraints imposed by the vendor's metrology, requirements for LLNL metrology, and datum definitions needed for mechanical assembly of the PO Box. In addition, each of the degrees of freedom of the substrate has been properly constrained and shown to be sufficiently insensitive to disturbance forces for minimizing deformation.

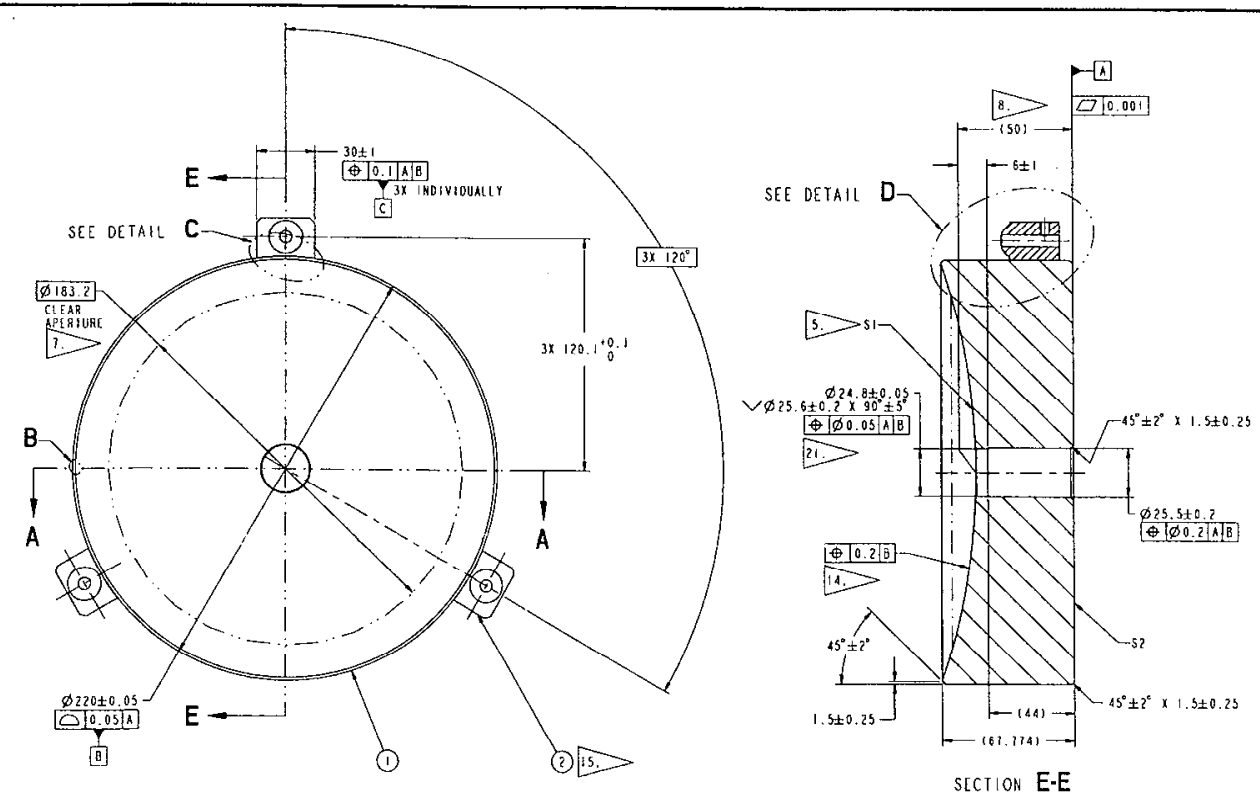

Figure 2. The main views from the M2 optic drawing.

A formal drawing of the M2 substrate is complete and was enclosed with the Milestone Report for M2. The M2 substrate is greater than twice the size of M1. Its outside diameter of $220 \mathrm{~mm}$ approaches the limit of the vendor's processing equipment and of the reflectometer used in evaluating the multilayer coating. The freeboard region outside the 
clear aperture is approximately $18 \mathrm{~mm}$ and is adequate for fabrication. A sensitivity study using finite element analysis showed a slight benefit to using a larger diameter but not sufficient enough to incur size limitation problems. The substrate's thickness has a greater impact on the sensitivity to mount-induced deformations. A thicker substrate is stiffer with lower sensitivity, while a thinner substrate offers greater clearance to the fold mirror that directs light to the mask. Of the two thicknesses that were analyzed, 50 and $60 \mathrm{~mm}$ center thickness, the $50 \mathrm{~mm}$ thickness provided adequate stiffness and was chosen primarily for clearance considerations. The definition of the datum surfaces chosen for the M2 substrate follow the same strategy in fixturing the M1 substrate to the Zeiss interferometer and to the PO Box. All of these decisions have been completed and incorporated into the final design drawing, a portion of which is shown in Figure 2.

\section{Milestone 5: Predicted aerial images from camera}

A report entitled, "Micro-Exposure Tool (MET) process windows and printing linearity," was submitted and approved against Milestone 5 during Q4-1999. This study examined the lithographic performance of the imaging system by computing the exposure-defocus (ED) characteristics for both the $50 \mathrm{~nm}$ and $35 \mathrm{~nm}$ technology nodes. Feature type effects (dense vs. isolated) and feature size effects (linearity) were studied by characterizing the resolution, process window and linearity. Several conclusions were reached. The first is the central obscuration had little or no impact on the resolution, process latitude or linearity from $120 \mathrm{~nm}$ to $20 \mathrm{~nm}$ linewidths (NA $=0.3, \sigma=0.7$ ). The second is the MET will meet the stated resolution targets with good process latitude.

Figure 3 illustrates part of the detailed analysis found in the report. At nominal focus, the exposure latitude (ELAT) for $50 \mathrm{~nm}$ dense L/S (100 nm pitch) was approximately $\pm 30 \%$, assuming an allowable $\mathrm{CD}$ variation of $\pm 10 \%$. Assuming an ELAT of $10 \%$, the maximum depth of focus for this geometry is $\sim 300 \mathrm{~nm}$. As expected, the process latitude shrinks for isolated features at the $50 \mathrm{~nm}$ generation ( $35 \mathrm{~nm}$ per the ITRS), where at nominal focus,
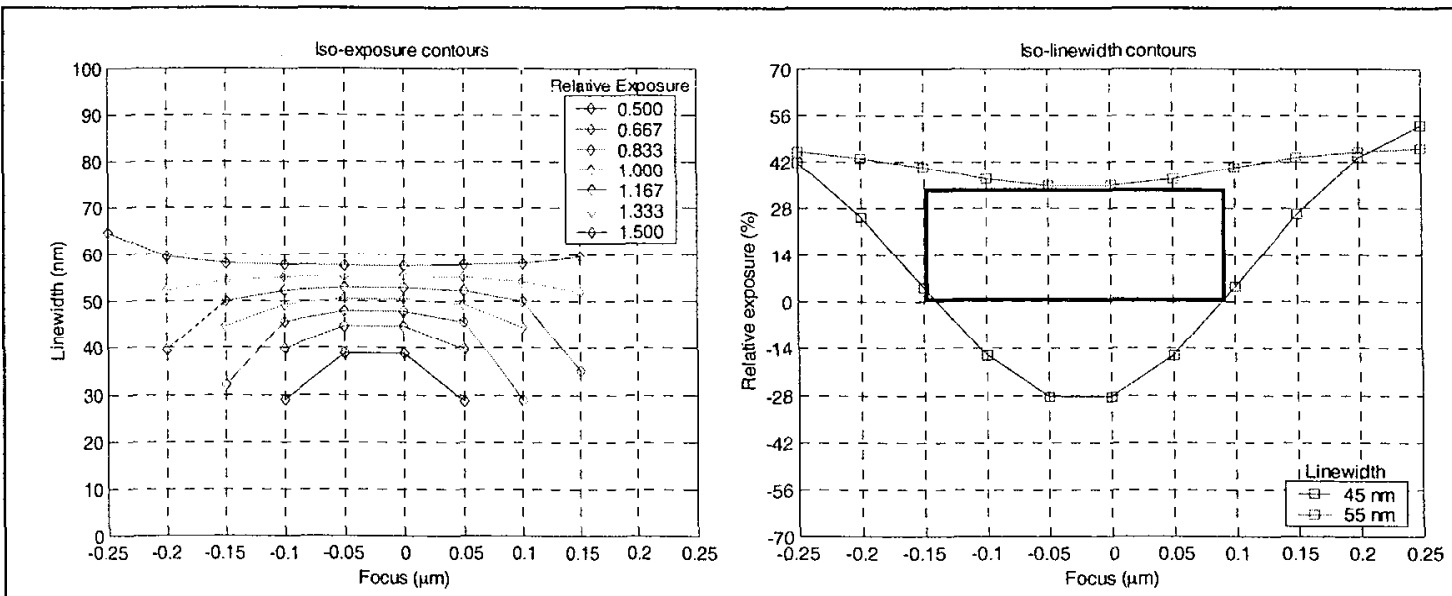

Figure 3. ED iso-exposure contours (top) and ED iso-linewidth contours (bottom) for $\mathbf{5 0} \mathbf{~ n m}$ dense lines with a $100 \mathrm{~nm}$ pitch. Iso-linewidth contours correspond to $\pm 10 \%$ linewidth tolerance. Box indicates maximum process latitude area. 
the exposure latitude is $\pm 18 \%$. However, for any given exposure level there was a reduction in the available depth of focus. The total depth of focus is $\sim 200 \mathrm{~nm}$ based on a $10 \%$ variation in exposure.

The ED analysis for the $35 \mathrm{~nm}$ technology node was also performed using $35 \mathrm{~nm}$ dense and $23 \mathrm{~nm}$ isolated features (ITRS roadmap). The same trends observed at the $50 \mathrm{~nm}$ node are observed at the $35 \mathrm{~nm}$ node. There is a slight shift in "best" focus to achieve the nominal CD at the nominal exposure and the process latitude is greater for the dense features. For the dense feature geometry, the maximum process window has a $15 \%$ ELAT over a depth of focus is $\sim 200 \mathrm{~nm}$ (assuming a $\pm 10 \%$ linewidth variation). Printing isolated features requires tighter process control. At a relative exposure variation of $\pm 5 \%$, the depth of focus shrinks to $\sim 125 \mathrm{~nm}$. This reduction in depth of focus can be partially overcome by using mask bias and overexposure, which is a topic of further study.

\section{Milestone 6: Specification package for the multilayer coatings}

The influence of multilayer coatings on MET performance was addressed during Q4-1999. We found that the incidence angles were sufficiently well-controlled to allow uniform $\mathrm{Mo} / \mathrm{Si}$ multilayers to be used. The multilayers cause a simple focus shift on the order of $\sim 100 \mathrm{~nm}$, but otherwise do not impact the imaging characteristics. Figure 4 illustrates optical path difference (OPD) maps from the nominal projection system and with $\mathrm{Mo} / \mathrm{Si}$ multilayer coatings added. In each case, the residual as-designed RMS wavefront error (less focus) was found to be $0.09 \mathrm{~nm}$.
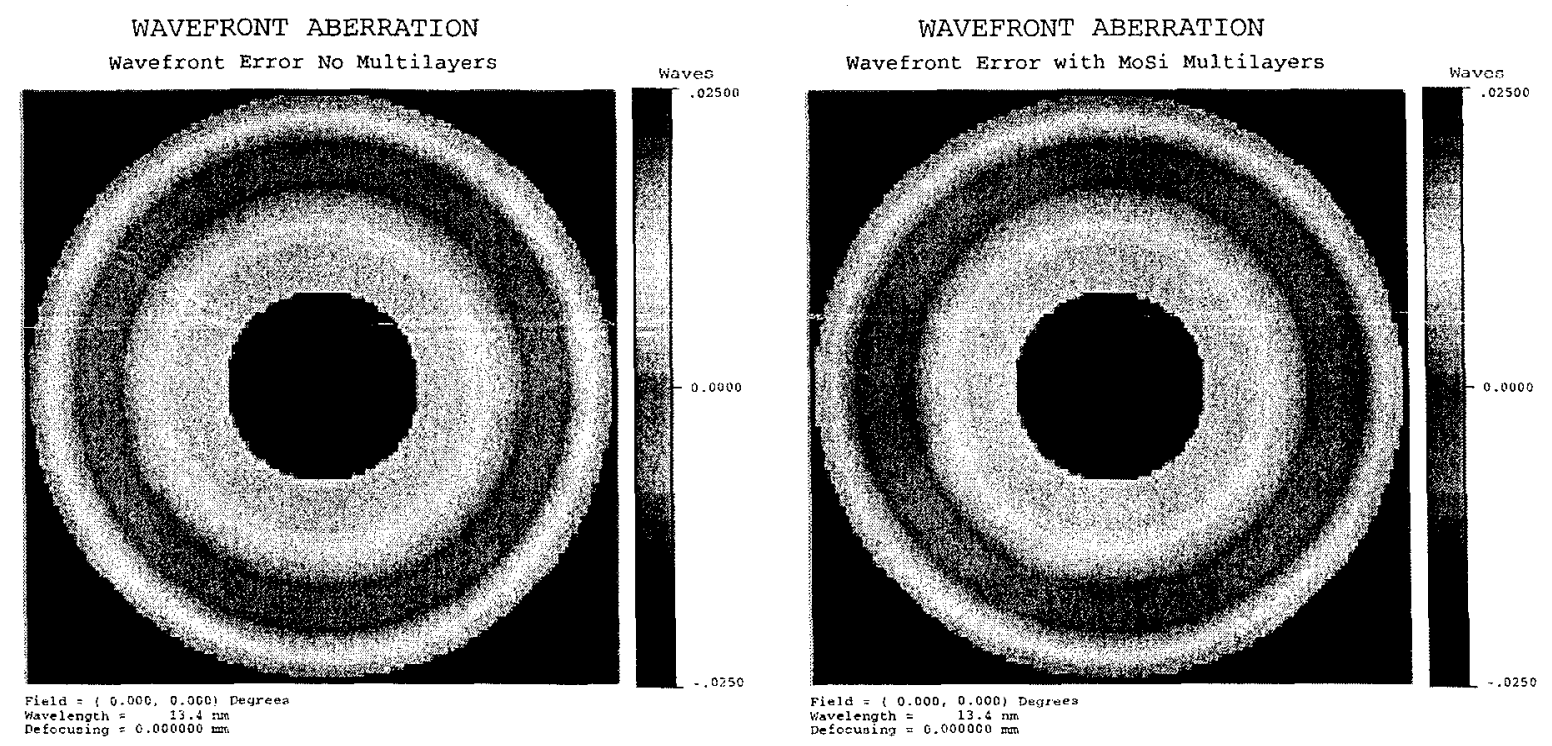

Figure 4. Optical path difference (OPD) maps for the nominal high NA microstepper (left) and with (right) multilayer coatings. In each case, the residual RMS wavefront error is $0.09 \mathrm{~nm}$, proving that uniform $\mathrm{Mo} / \mathrm{Si}$ multilayers do not alter the residual wavefront error as-designed at any field point. Therefore, the coatings do not impact the lithographic printing characteristics of the camera. 
A set of multilayer tolerances for the MET camera was derived and summarized in a Milestone Report entitled, "Multilayer specifications for the MET projection camera." This report was delivered to International Sematech (Neil Wester) during Q4-1999.

Milestone 7: Prediction of printed images of characteristic mask defects 7a: Preliminary 7b: Final

During the quarter, we began studying how mask defects will print in the MET. Although extensive printable defect modeling is currently being performed within the VNL, it is important to develop MET specific models to describe printing for several reasons. The first is that the MET is a static imager and does not benefit from scan-averaging of aberrations as in the ETS. That means that variations in wavefront aberration across the field of view will cause variations in $\mathrm{CD}$ for a specific threshold level. Important questions include how the $\mathrm{CD}$ will vary due to wavefront error variations or from defect location within the field of view. Secondly, the MET has a central obscuration that changes the image log slope when compared to an equivalent unobscured system. Defects will interact differently with features due to the change in image log slope (ILS). Finally, a proposed plan is to vary the NA in the MET using different aperture stops. In this case, the obscured area is fixed, so the ILS will vary as a function of obscured pupil area relative to the numerical aperture, again leading to different interactions between the defect and the feature.

We plan to use an internal LLNL code, TSARLITE, coupled with the Stearns multilayer growth model to compute the amplitude and phase variations due to defects at the surface of the mask. Using this data, a gray-scale mask file is generated which is then input into Prolith to simulate the partially coherent image formation taking into account the aberrations and obscuration present in the MET.

Figures 5 and 6 show initial calculations of printed defects, where, in each case, a defect was added to a mask consisting of $350 \mathrm{~nm}$ lines and spaces. Imaging at the 5x MET reduction yields features at the wafer of $70 \mathrm{~nm}$. The numerical aperture was set 100.30 , and the partial coherence was set to 0.70 . This simulation included the central obscuration and the aberrations at the central field point as well. In both cases the defect was place between the second (L2) and third (L3) lines. Figure 5 shows the aerial image using a $10 \mathrm{~nm}$ defect, while Figure 6 show the aerial image with a $90 \mathrm{~nm}$ defect. The change in linewidth and loss in image log slope is easily seen in Figure 6, which qualitatively yields the anticipated result.

These aerial images demonstrate that the link between TSARLITE and PROLITH has been established in the context of the MET. Work is currently in progress to quantify the change in $\mathrm{CD}$ caused by various defects at specified threshold levels. Delivery of the report for Milestone 7 is planned for February 2000. 


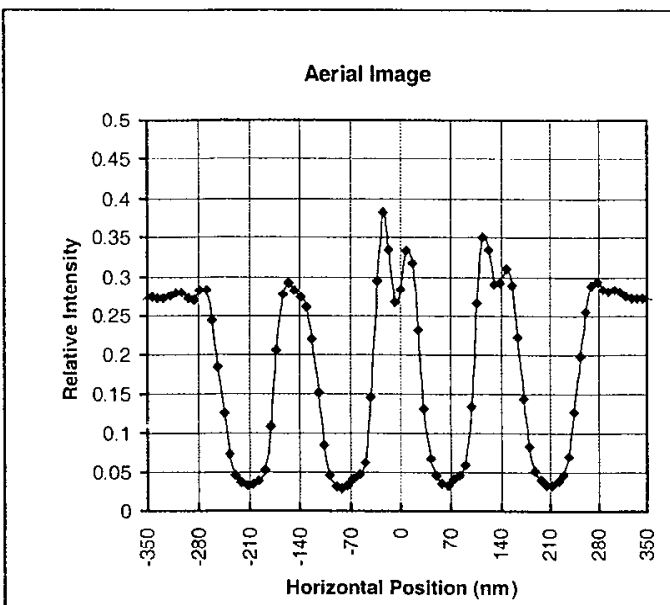

Figure 5. Aerial image of 4 lines including a $10 \mathrm{~nm}$ mask substrate defect in the space between $L 2$ and L3. Simulation shows that this $10 \mathrm{~nm}$ defect will not print when imaged in the MET (NA $=0.30, \sigma=0.70$, obscuration included).

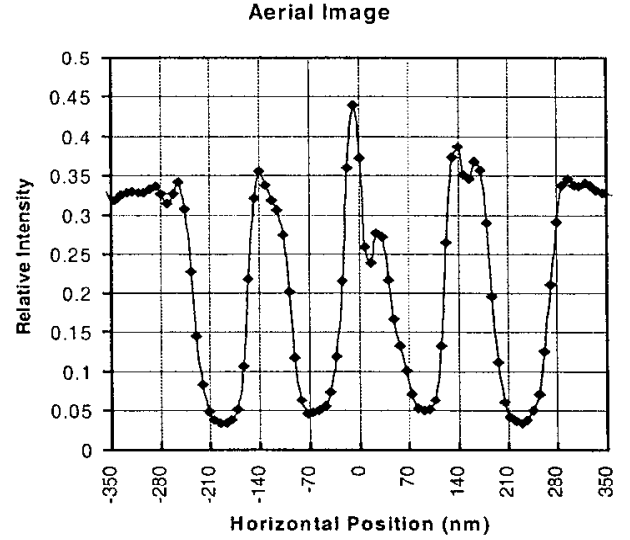

Figure 6. Aerial image of 4 lines including a $90 \mathrm{~nm}$ mask substrate defect in the space between $L 2$ and $L 3$. This $90 \mathrm{~nm}$ defect will print when imaged in the MET $(\mathrm{NA}=0.30$, $\sigma=\mathbf{0 . 7 0}$, obscuration included).

Milestone 8: Validation of vendor metrology

8a: Validation Plan 8b: Validation Results

A plan to validate the Zeiss metrology for the primary mirror in the MET camera was developed and presented to Neil Wester of International SEMATECH on December 16, 1999. The validation plan was approved and accepted, satisfying this milestone. The central idea behind the plan is to use the existing M3 PSDI for the ETS and make minor retrofits to accommodate the MET M1 test geometry. Figure 7 illustrates the core of the technical approach.

Our plan to retrofit the ETS M3 cavity leverages many of the developments and error reduction strategies used on the ETS optics. For example, the imaging system will be rotated to remove systematic errors associated with the imaging lens. Also, a distortion calibration grid will be used to ensure an accurate coordinate mapping between the test optic and the CCD camera. Since the MET primary is rotationally symmetric, it would also be beneficial to perform rotational averaging by rotating the M1 mirror itself with respect to the rest of the test cavity. This would reduce systematic errors associated with the imperfections in the surface finish of the interferometer optics, including the converging lens. However, given the progress in meeting the ETS metrology milestones, we feel that the current approach offers an optimal balance between validating the Zeiss metrology while staying within the High NA Optics program budget.

We estimate that the MET PSDI will support the validation of the M1 absolute figure accuracy specification of $0.25 \mathrm{~nm}$ rms. 


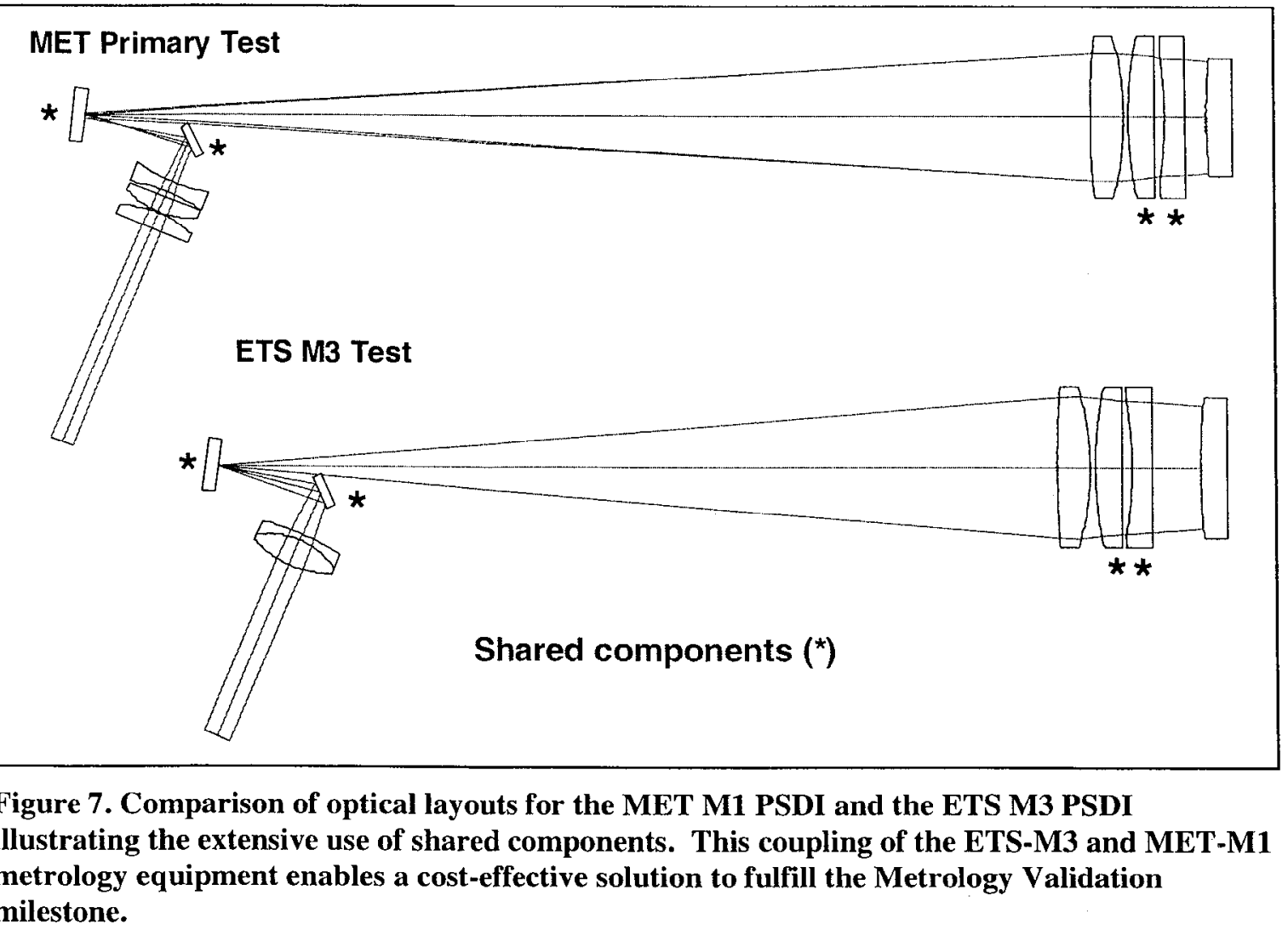
milestone.

\section{Milestone 9: Delivery of the polished substrates}

$$
\text { 9a: M1 9b: M2 }
$$

To support the Zeiss schedule for optical fabrication, numerous tasks and design issues have been addressed. Efforts supporting the M1 substrate were reported in the Q3-1999 Quarterly Report, while tasks supporting the M2 substrate are reported here. The original schedule called for Zeiss to converge to their figure metrology by November 30, 1999, with certification of accuracy during December. However, Zeiss has been unable to meet the proposed fabrication schedule for M1 due to difficulties in simultaneously achieving figure and finish. In order to minimize the schedule impact for M2 and the alignment of the PO Box, Zeiss is constructing a separate interferometer for initiating fabrication of M2. Their original plan included the conversion of the M1 interferometer for use on the M2. Zeiss anticipates delivering the M1 substrate for metrology validation during March-April 2000 .

The designs of the M2 mounting interface (i.e., the button detail) and the M2 metrology mount are complete, and procurements are proceeding with ample time to meet a midFebruary need date. The design of the gluing fixture is also complete and fabrication will proceed in January. Many of the mounting issues for the M2 optic were addressed 
previously with the M1 optic. The M2 button detail is essentially a scaled version of the M1 button with one minor exception. The M2 metrology mount is physically larger than the M1 and forms an annulus around the optic to better interface with the interferometer, which lies below the optic. Like the M1 metrology mount, three pairs of rollers are used to exactly constrain the optic's six rigid-body degrees of freedom through three partial spheres, one on each button. As shown in Figure 8, each roller translates on a rollingelement bearing that provides very low friction for both linear and rotary motion. An error budget analysis indicates that the much heavier M2 optic would be too sensitive to use sliding friction for the linear bearing as was done for the M1 optic. In the milestone report for the M2 specification package, the M2 error budget shows that the total mount-induced figure error is $0.021 \mathrm{~nm}$ rms assuming an root-sum-squared (RSS) combination from three supports.

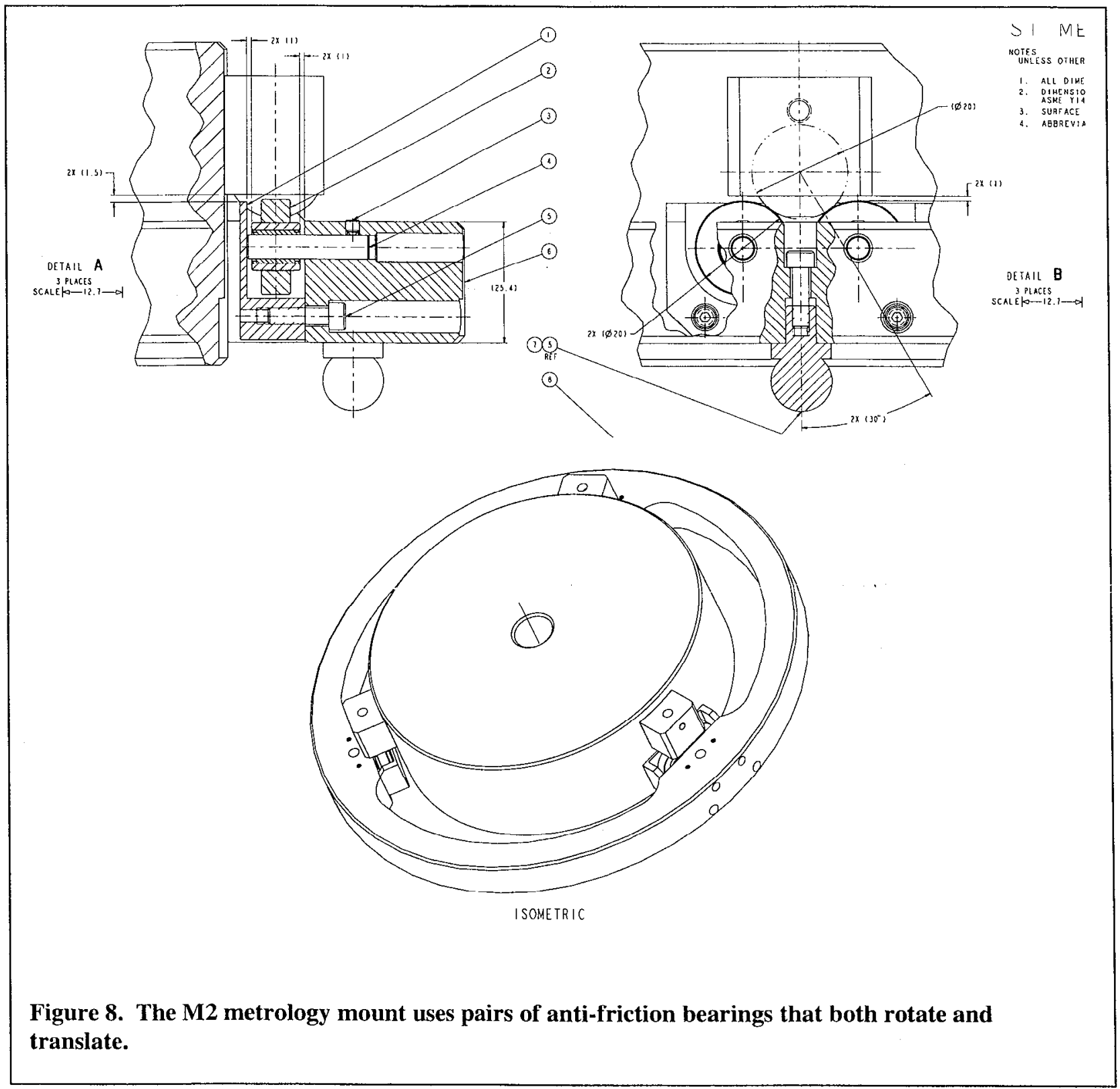


Milestone 10: Delivery of the multilayer coated substrates

Planning has begun for this task. However, hardware preparation will not begin until Q1Q2 2000. We anticipate completing this task on the scheduled dates.

\section{Milestone 11: Multilayer coating metrology}

This task supports the multilayer coating effort and will not be directly addressed until Q1Q2 2000. However discussions have begun on designing fixtures for mounting the elements within the ALS reflectometer. 


\section{Milestone Chart}

\begin{tabular}{|c|c|c|c|c|c|}
\hline $\mathrm{M} / \mathrm{S}$ & Description & $\begin{array}{c}\text { Task } \\
\text { Section }\end{array}$ & $\begin{array}{l}\text { Deliverable } \\
\text { Section }\end{array}$ & Status & $\begin{array}{l}\text { Due } \\
\text { Date }\end{array}$ \\
\hline 1 & $\begin{array}{l}\text { Award contract for fabrication and } \\
\text { testing of two aspheric mirrors; } \\
\text { Prepayment to vendor to initiate } \\
\text { work. }\end{array}$ & 3.1 .6 & 8.1 .6 & Done & $8 / 31 / 99$ \\
\hline 2 & $\begin{array}{l}\text { Award contract for multilayer } \\
\text { coatings. }\end{array}$ & 3.1 .7 & 8.1 .5 & Done & $8 / 31 / 99$ \\
\hline 3 & $\begin{array}{l}\text { Optical design package for EUV } \\
\text { imaging system employing two } \\
\text { aspheric mirrors }\end{array}$ & 3.1 .1 & 8.1 .1 & Done & $9 / 24 / 99$ \\
\hline 4 & $\begin{array}{l}\text { Specification package for the } \\
\text { individual coated mirror substrates. } \\
\text { Mx a }(x=1,2) \text { : Preliminary } \\
\text { Mx b: Final }\end{array}$ & 3.1 .4 & 8.1 .4 & $\begin{array}{l}\text { M1 (a,b): } \\
\text { Done } \\
\text { M2(a): } \\
\text { Done } \\
\text { M2(b): } \\
\text { In-process }\end{array}$ & $\begin{array}{l}\text { M1 a: } 9 / 24 / 99 \\
\text { M2 a: } 11 / 30 / 99 \\
\text { M1 b: } 9 / 24 / 99 \\
\text { M2 b: } 12 / 22 / 99\end{array}$ \\
\hline 5 & $\begin{array}{l}\text { Predicted aerial images from } \\
\text { camera }\end{array}$ & 3.1 .2 & 8.1 .2 & Done & $10 / 22 / 99$ \\
\hline 6 & $\begin{array}{l}\text { Specification package for } \\
\text { multilayer coatings }\end{array}$ & 3.1 .5 & 8.1 .5 & Done & $11 / 19 / 99$ \\
\hline 7 & $\begin{array}{l}\text { Prediction of printed images of } \\
\text { characteristic mask defects. } \\
\text { a: Preliminary } \\
\text { b: Final }\end{array}$ & 3.1 .3 & 8.1 .3 & In-process & $\begin{array}{l}\text { a: } 11 / 30 / 99 \\
\text { b: } 12 / 22 / 99\end{array}$ \\
\hline 8 & $\begin{array}{l}\text { Validation of vendor metrology. } \\
\text { a: Validation plan } \\
\text { b: Validation results }\end{array}$ & 3.1 .8 & 8.1 .7 & $\begin{array}{l}\text { a: Done } \\
\text { b: In- } \\
\text { process }\end{array}$ & $\begin{array}{l}\text { a: } 11 / 30 / 99 \\
\text { b: } 5 / 12 / 00\end{array}$ \\
\hline 9 & $\begin{array}{l}\text { Delivery of polished substrates. } \\
\text { a: M1 substrate } \\
\text { b: M2 substrate }\end{array}$ & 3.1 .6 & 8.1 .6 & $\begin{array}{l}\text { a, b: } \\
\text { In-process }\end{array}$ & $\begin{array}{l}\text { a: } 4 / 14 / 00 \\
\text { b: } 5 / 12 / 00\end{array}$ \\
\hline 10 & $\begin{array}{l}\text { Delivery of multilayer coated } \\
\text { substrates }\end{array}$ & 3.1 .7 & 8.1 .8 & In-process & $6 / 9 / 00$ \\
\hline 11 & Multilayer coating metrology & 3.1 .7 & 8.1 .8 & In-process & $6 / 23 / 00$ \\
\hline
\end{tabular}

\section{Auspices}

This work was performed under the auspices of the U.S. Department of Energy by the Lawrence Livermore National Laboratory under Contract No. W-7405-ENG-48. Funding was provided by the Extreme Ultraviolet Limited Liability Corporation under a Cooperative Research and Development Agreement. This effort is in support of International Sematech Project \#LITH112 -- High-NA EUV Optics for Mask Defect Printability Scaling under the administration of Neil Wester. 